\title{
FINITE ELEMENT ANALYSIS OF DEMOUNTABLE STEEL-CONCRETE COMPOSITE BEAMS UNDER STATIC LOADING
}

\author{
V.I. Patel ${ }^{1,2^{*}}$, B. Uy ${ }^{2,3}$, S.W. Pathirana ${ }^{2}$, S. Wood ${ }^{2}$, M. Singh ${ }^{2}$ and B. T. Trang ${ }^{2}$ \\ ${ }^{I}$ School of Engineering and Mathematical Sciences, La Trobe University, \\ Bendigo, VIC 3552, Australia \\ ${ }^{2}$ Centre for Infrastructure Engineering and Safety, School of Civil and Environmental Engineering, \\ The University of New South Wales, NSW 2232, Australia \\ ${ }^{3}$ School of Civil Engineering, The University of Sydney, Sydney, NSW 2006, Australia \\ *(Corresponding author: E-mail:v.patel@latrobe.edu.au)
}

Received: 29 August 2016; Revised: 23 June 2017; Accepted: 20 August 2017

\begin{abstract}
This paper investigates the innovative beam-slab connectors to enable steel-concrete framed structures to be made demountable. A computational simulation for determining the fundamental performance of the demountable composite beams with hollow core concrete slabs, profiled steel deck and bolted shear connectors is developed using the computational code ABAQUS. This numerical model was employed to compare the strength, stiffness and ductility of conventional composite beams utilising welded shear connectors with that of demountable steel-concrete beams utilising blind bolts. The bolted shear connectors not only overcome problems that prevent rehabilitation of existing composite beams with headed studs but also allow for the demountability in the composite beams. The adequacy of the developed computational models is evaluated by verifying the computational results against the corresponding experimental performance. The verification demonstrates that the computational simulations agree with the test performance. The numerical prediction indicated that the shear capacity of blind bolts used in demountable composite metal decking slabs is higher than that of welded connectors utilised in the conventional steel-concrete composite beams. It is found that the composite beams with bolted connectors can be made demountable up to a load of about $50 \%$ of the ultimate load which is greater than typical service loads. The strength of shear connectors obtained from the finite element models and experiments were compared with the predicted strength using Eurocode 4 and AS2327.1-2003. It appears that Eurocode 4 and AS2327.1-2003 provide the conservative solutions for the design of shear connector strengths.
\end{abstract}

Keywords: Demountable composite beams, bolted connectors, finite element analysis, profile slabs, solid slabs, blind bolts

DOI: $10.18057 /$ IJASC.2018.14.3.5

\section{INTRODUCTION}

The global carbon emission promotes the sustainable concept of reusing the structural members. This can be achieved through changes in the constructional methods including structures to be made demountable. The steel-concrete composite beams provide the construction economy in steel-concrete framed structures owing to the combine contribution achieved from the steel beam and concrete slabs. A current construction method uses headed studs to develop the steel-concrete combine contribution. The headed studs are permanently welded over a metal deck on the steel beams before casting the concrete slabs. This constructional practice does not allow the steel-concrete composite beams to be made demountable. Therefore, structural steels used in steel-concrete composite beams need to be recycled before reusing them. However, the recycling of structural steels consumes approximately the same energy when compare with the energy consumption for manufacturing the steels from scratch. 
This paper employs blind bolts in composite beams which allow these beams to be made demountable. The reusing of structural steels instead of recycling them has a great potential to provide cost effective systems and environmental benefits for constructions. The bolted shear connectors in preference to headed studs can be utilized to make composite beams demountable. Their use facilitates the deconstruction of structural elements in composite buildings. Performances of demountable steel-concrete beams with blind bolts, profiled steel decks and hollowcore planks have not been addressed previously. Therefore, this investigation presents the stiffness, strength and ductility of the demountable composite beams. Figure 1 illustrates the proposed demountable steel-concrete composite beams. The steel beams have predrilled holes on the flanges of their steel beams. The blind bolts are connected with the steel flange passing through pre-drilled holes. Oversized holes for tolerances used in the current construction practice are utilized to achieve demountability. The bolts can be removed as the head is situated on the exterior of the steel beam flange. The bolt arrangement is shown in Figure 2.

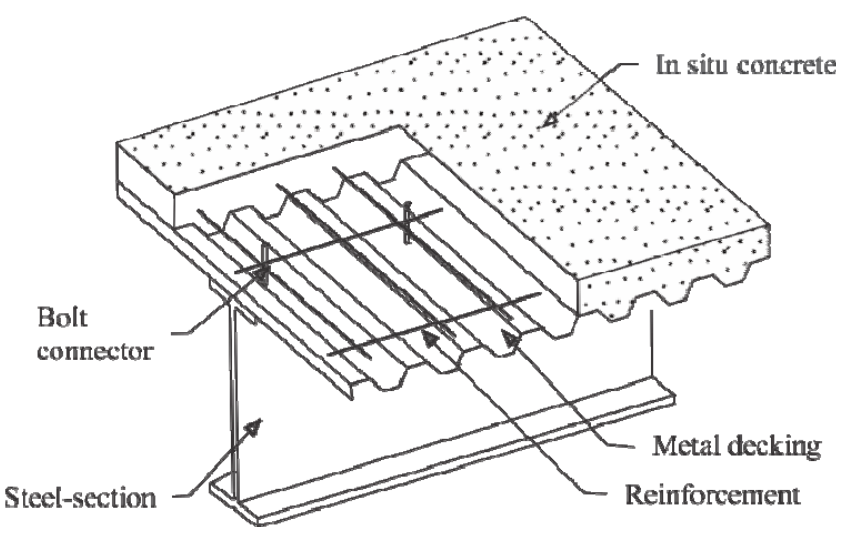

(a) Trapezoidal profiled steel deck

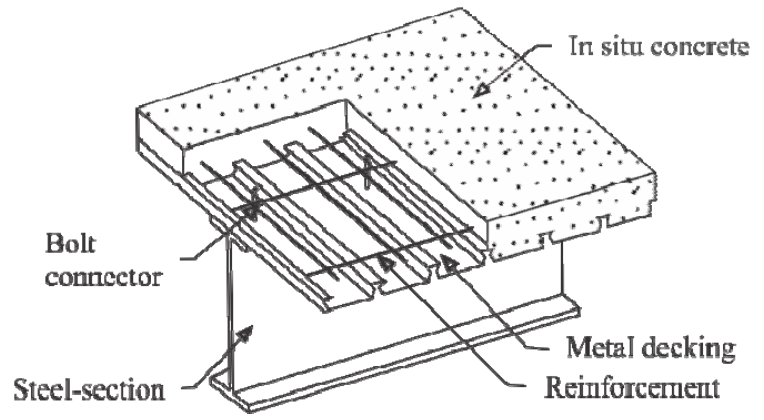

(b) Re-entrant profiled steel deck

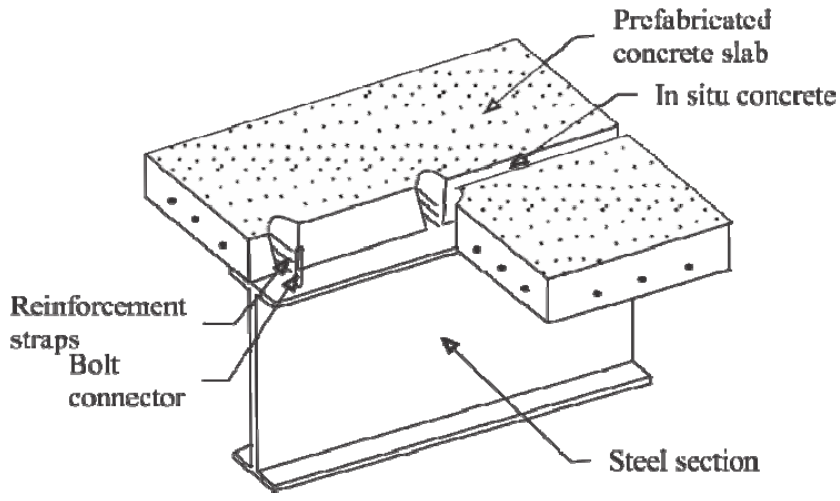

(c) Hollow-core concrete slab

Figure 1. Demountable Steel-concrete Composite Beams with Bolted Connectors 


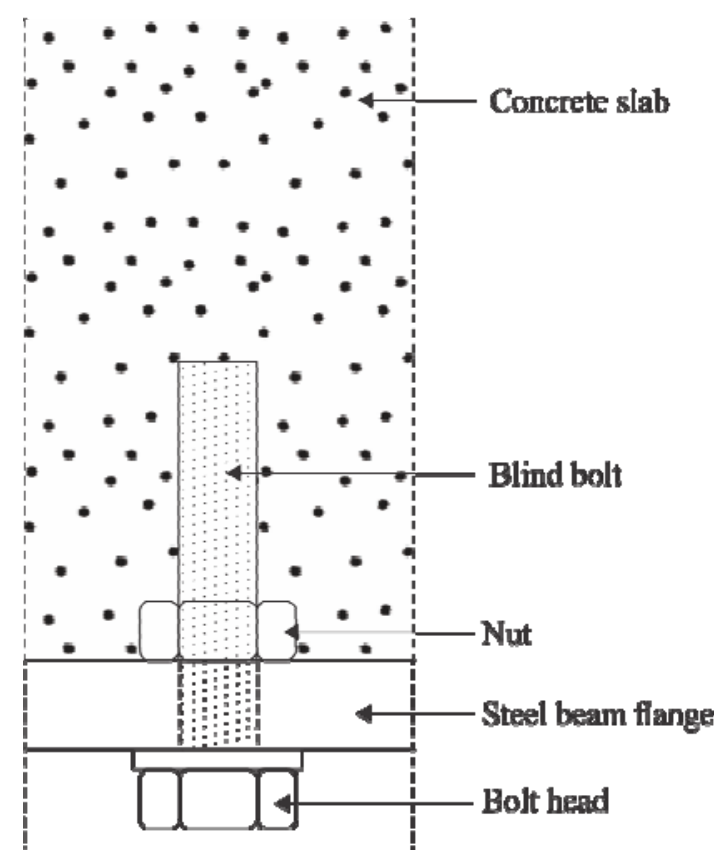

Figure 2. Bolt Arrangement in Demountable Composite Beams

Many research studies have been carried out in recent years to evaluate the shear connector behaviour for demountable construction. Lam et al. [1-2] conducted the study on the composite behavior of precast concrete slabs on steel beams. The results indicated that the stud shear capacity is affected by stud shear tensile strength, gap width, reinforcement ratio and concrete strength. Ellobody and Young [3] conducted the finite element analysis of steel-concrete beams with profiled sheeting. They reported that Eurocode 4 [4] provides the conservative solution for predicting the shear strength of composite beams. Four push-out tests on the prefabricated concrete slabs with high strength bolts and headed studs subjected to static loading were performed by Pavlović et al. [5] to evaluate the bolted shear connector performance. Test results indicated that the bolted shear connectors achieved approximately $95 \%$ of the shear strength of the welded shear studs under static shear force. However, the stiffness of the bolted connectors was $50 \%$ lesser than the stiffness of the headed studs. Previous experimental research into the demountable solid slabs and composite slabs with bolted shear connectors was conducted by Dai et al. [6], Rehman et al. [7] and Moynihan and Allwood [8]. They concluded that the steel-concrete beams were failed by concrete crushing and connector fracture. The shear resistance was achieved about $84 \%$ of the headed studs at the slip of 6 mm. Further tests on full scale beams by Mirza and Uy [9] and Pathirana et al. [10-11] illustrated that the steel-concrete composite beams could be loaded to very high service loads and the blind bolts could still be removed. The experimental studies conducted by Loh et al. [12], Wang et al. [13] and Mirza and Uy [14] illustrated the benefits of using blind bolts connections to concrete-filled steel tubular columns. These types of joints can be made demountable as illustrated by Liu et al. [15] and Ataei et al. [16]. The numerical research on the computational analysis of the demountable composite beams utilizing profiled steel decks and blind bolts was performed by Ban et al. [17] and Uy et al. [18] who concluded that the structural connections can be demounted at approximately $50 \%$ of the ultimate load.

The composite beam exhibits not only the axial compression or tension but also the hogging or sagging bending moments. Vasdravellis et al. [19-22] studied the behaviour of composite beams under the effects of sagging-hogging bending moments and axial compression-tension. The results indicated that ultimate moment capacity of a composite beam is considerably decreased when the compression or tension load applies in the composite section. It is also noted that the local buckling 
of the steel beam for these combined loading conditions is found to be more pronounced which reduces the ductility of composite section. It is suggested that the use of longitudinal stiffeners in the web of the steel beams at the internal support regions of continuous beam reduces the web buckling and increase the rotational capacity of the composite section. A simple design equation is proposed for determining the interaction of axial compression and bending moments of the composite beams.

Further research on the demountable connections for the composite metal decking beams is needed. In addition, the hollowcore planks on steel beams are also a very popular method of construction and demountable connection to these structural forms needs to be evaluated. The broad purpose of this paper is to promote the reuse of structural members by utilizing innovative beam-slab connectors that allow demountability in composite steel-concrete beams with hollow core concrete slab and steel decks. The Dassault Systemes SIMULA Abaqus program was utilized for the simulation of demountable composite beams. Two profiled steel decks, trapezoidal and re-entrant profiled steel deck were considered in the computational analysis. High strength blind bolts were used in the analysis of the demountable composite beams. The demountable composite metal decking beams were simulated by taking into account for the geometric and material nonlinearities. The finite element computational method was utilized to simulate the headed shear stud strength, bolted connector capacity, load-slip characteristics and modes of failure. The effects of concrete compressive strengths, slab types, shear connector types and metal decking thickness on the performance of the steel-concrete metal decking slabs were investigated. The developed computational models were utilized to examine the influences of these material and geometric variables on the strength, stiffness and ductility of the demountable composite beams. Finally, international standards were employed to predict the shear strength of connectors.

\section{COMPUTATIONAL ANALYSIS - FINITE ELEMENT METHOD}

\subsection{Basic Concept}

A three-dimensional half model of the steel-concrete beams was constructed for the nonlinear inelastic analysis using the ABAQUS finite element code [23]. Three models were developed for composite beams with blind bolts as depicted in Figure 3. The corresponding finite element model was also constructed for composite steel-concrete beam with headed studs. This computational model was assessed by verifying the predicted behaviour with test performance presented by Uy and Bradford [24] and Mirza et al. [25]. The finite element analysis was conducted using ABAQUS/Implicit static general procedure. Material stress-strain characteristics, surface-to-surface interactions, constraints and boundary conditions were defined to accurately simulate the experimental performance.

\subsection{Geometry, Finite Element Types and Mesh Size}

The steel-concrete composite beams with metal decking slab and hollow core concrete slab are shown in Figure 3. The geometric and material properties for steel beams, bolts and concrete are considered based on the current limits set in the various Australian Standards [26-29]. The composite metal decking beams were symmetrical in the longitudinal direction so only half 3-D model was constructed to minimize the computational time. The steel beams, blind bolts, headed studs and concrete slabs were discretized using the eight-node linear hexahedral solid elements with reduced integration and hourglass control (C3D8R). The finite elements with reduced-integration were selected because they reduced the analysis time. These finite elements were employed with a fine mesh to maintain the accuracy of the simulation. A sensitivity study was 
conducted to evaluate the reasonable mesh size. The reinforcing bars were meshed with two-node linear three-dimensional truss elements (T3D3). The typical geometries and element types used in modelling of the composite metal decking beams are illustrated in Figure 4.

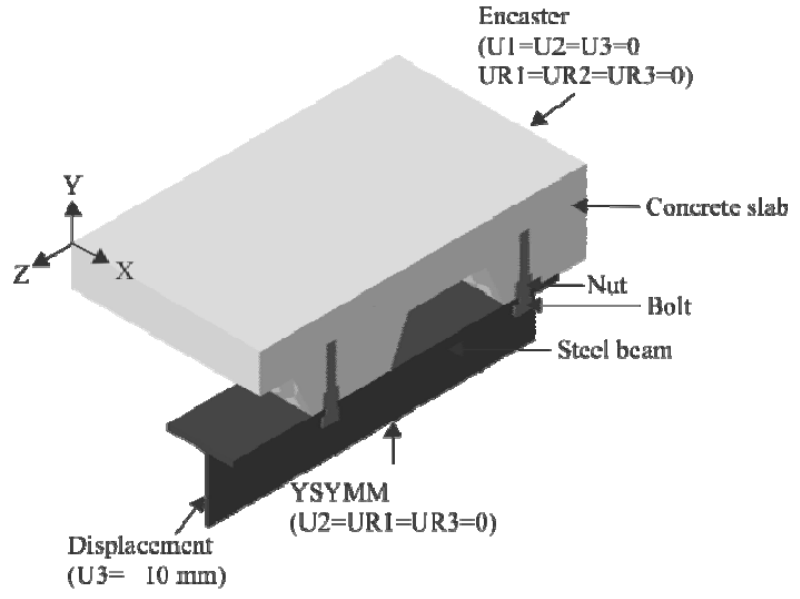

(a) Trapezoidal profiled deck

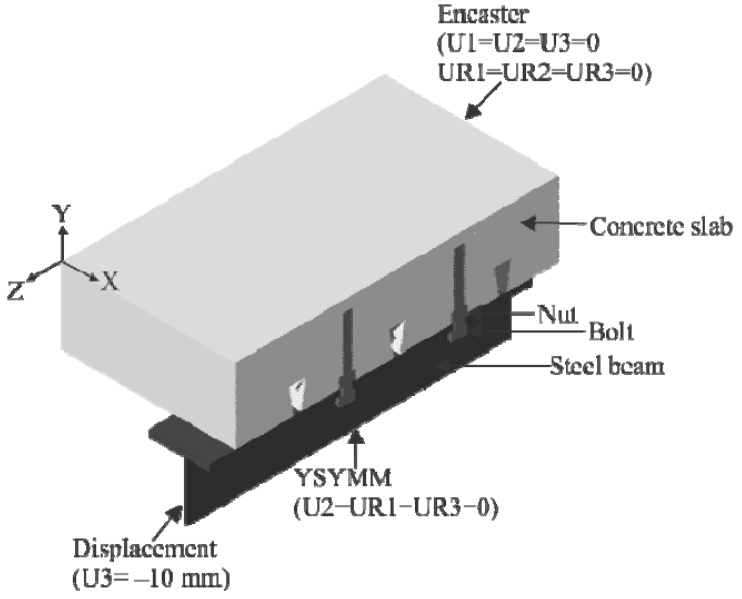

(b) Re-entrant profiled steel deck

\section{Encaster}

$(\mathrm{U} 1=\mathrm{U} 2=\mathrm{U} 3=\mathrm{UR} \mathrm{I}=\mathrm{UR} 2=\mathrm{UR} 3=0$ )

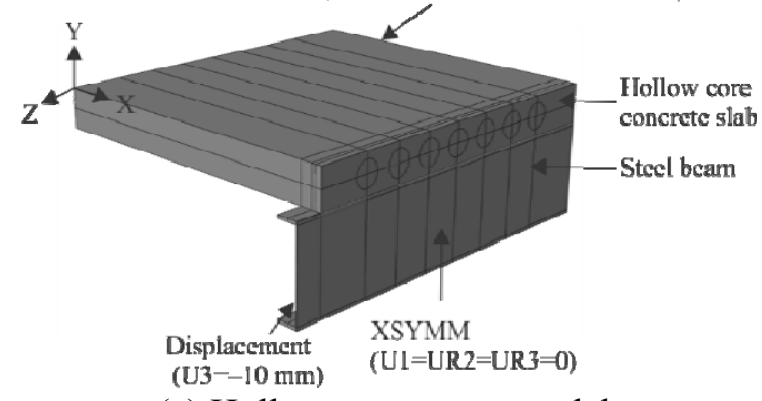

(c) Hollow core concrete slab

Figure 3. Finite Element Models for Demountable Composite Beams

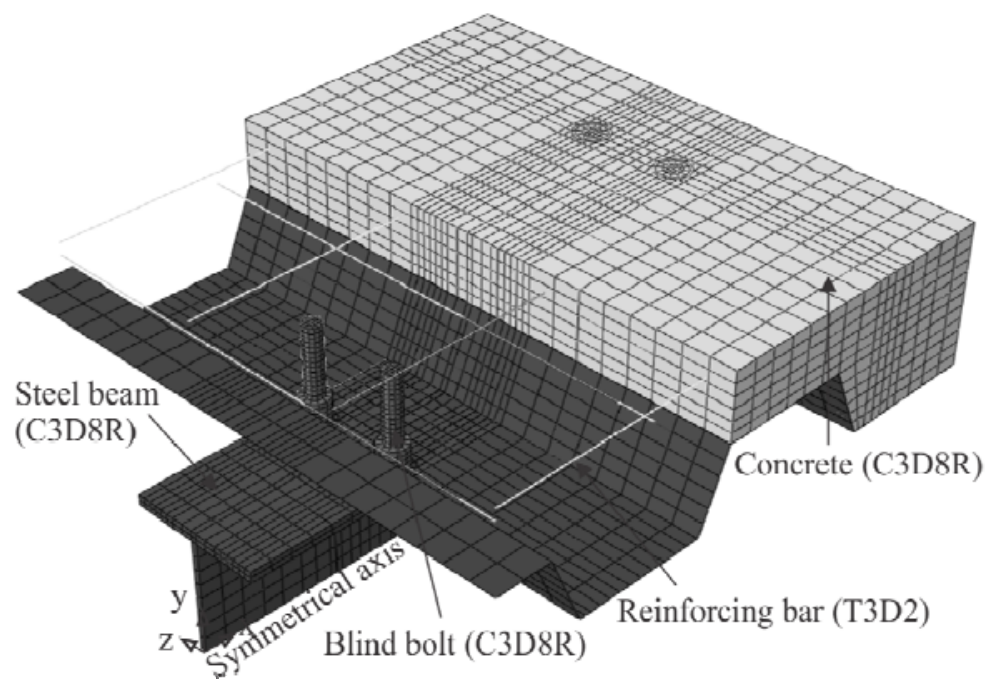

Figure 4. Finite Element Models with Geometries, Mesh Size and Element Types 


\subsection{Surface-To-Surface Interaction, Boundary Conditions and Load}

Appropriate constrains were used to define the interaction between beam and bolt, decking and bolt, concrete and bolt, decking and concrete, decking and beam and bolts and nuts. The surface-to-surface contact with finite sliding was employed. The penetration between the contacted components was restricted by using 'Hard Contact' in the normal direction. The tangential characteristic of the contact was simulated by selecting the penalty friction formulation. The surface-to-surface interactions of the composite metal decking beam components are listed in Table 1. As shown in Figure 5(a), the surface-to-surface interaction was applied to the steel beam and bolt surfaces. The steel flange surfaces were taken as a master surface and the bolt shank surfaces were selected as a slave surface. It can be seen from Figure 5(b) that the contact between the decking and bolt was analyzed using the interaction algorithm. The decking and bolt surface is selected as a master and slave surface, respectively. The contact interaction was also used at the concrete-to-bolt (Figure 5c), decking-to-concrete (Figure 5d) and decking-to-beam (Figure 5e) interfaces. It was found from the push-out experiment that the nut surface did not separate from the bolt surface [11]. Therefore, the bolt and nut were created as a single part as shown in Figure 5(f). In addition, reinforcing rebar is located inside the concrete slab as depicted in Figure 4. The embedded element method was employed to model the rebar in the concrete slab. The embedded element method is utilized to specify an element which lie embedded in a host elements. The response of the host elements is used to constrain the translational degrees of freedom of the embedded nodes. In this analysis, the concrete slab is defined as host regions and the reinforcement is considered as embedded region. It is assumed that the perfect bond exists between the reinforcement and concrete [19].

Table 1. Surface-to-surface Interaction of Composite Beam Components

\begin{tabular}{|c|c|c|c|c|c|}
\hline \multirow[b]{2}{*}{ Name } & \multicolumn{2}{|c|}{ Surface selection } & \multirow[b]{2}{*}{$\begin{array}{l}\text { Contact } \\
\text { type }\end{array}$} & \multicolumn{2}{|c|}{ Interaction property } \\
\hline & $\begin{array}{l}\text { Master } \\
\text { surface }\end{array}$ & $\begin{array}{c}\text { Slave } \\
\text { surface }\end{array}$ & & $\begin{array}{l}\text { Tangential behaviour: } \\
\text { Friction coefficient }\end{array}$ & $\begin{array}{c}\text { Normal } \\
\text { behaviour }\end{array}$ \\
\hline Bolt-steel beam & Steel beam & Bolt & Interaction & 0.3 & Hard contact \\
\hline Bolt-steel deck & Steel deck & Bolt & Interaction & 0.3 & Hard contact \\
\hline Concrete slab-bolt & $\begin{array}{l}\text { Concrete } \\
\text { slab }\end{array}$ & Bolt & Interaction & 0.3 & Hard contact \\
\hline $\begin{array}{c}\text { Steel deck-concrete } \\
\text { slab }\end{array}$ & Steel deck & $\begin{array}{l}\text { Concrete } \\
\text { slab }\end{array}$ & Interaction & 0.3 & Hard contact \\
\hline Steel beam-steel deck & Steel deck & $\begin{array}{l}\text { Steel } \\
\text { beam }\end{array}$ & Interaction & 0.6 & Hard contact \\
\hline $\begin{array}{c}\text { Concrete } \\
\text { slab-reinforcement }\end{array}$ & - & - & Embedded & - & - \\
\hline
\end{tabular}

The symmetric boundary conditions were defined at the middle of the beam web. The symmetrical axis for the demountable composite metal decking beams is depicted in Figure 4. The surface along the middle of steel beam were restrained from translating in the $\mathrm{Y}$ direction and rotating about $\mathrm{X}$ and $\mathrm{Y}$ directions for applying the symmetrical conditions. The base of the concrete slab was fixed in all directions. This is to ensure that the concrete slab does not move, and only the steel beam is translated.

The simulation of the composite metal decking beams is generally conducted by using the static analysis procedure. A uniform displacement on the upper end of the beam was applied to model the loading used in the tests. A uniform displacement load of $-10 \mathrm{~mm}$ was applied. The nonlinear inelastic analysis of demountable composite beams requires multiple steps. The surface-to-surface interactions were established in the first step of analysis for the contact formulation which may cause the convergence problems in the consecutive steps. The bolted shear connectors were pre-tensioned to loads of $20 \mathrm{kN}$ in the second step. The deflection control method utilising the static general procedure is used in the nonlinear analysis to determine the slip and load in the third step. It 
should be noted that the analysis of composite beams generally faces the convergence problems. The initial increment in the analysis step was adjusted to overcome the convergence problems.

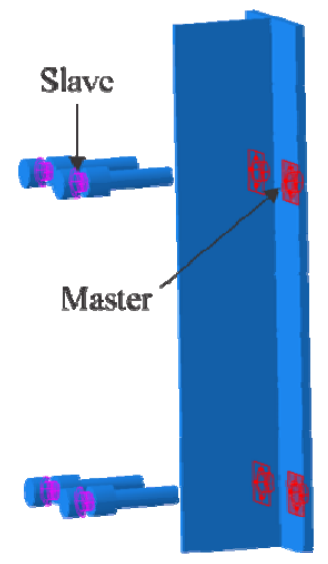

(a) Surfaces in contact interaction between beam and bolt

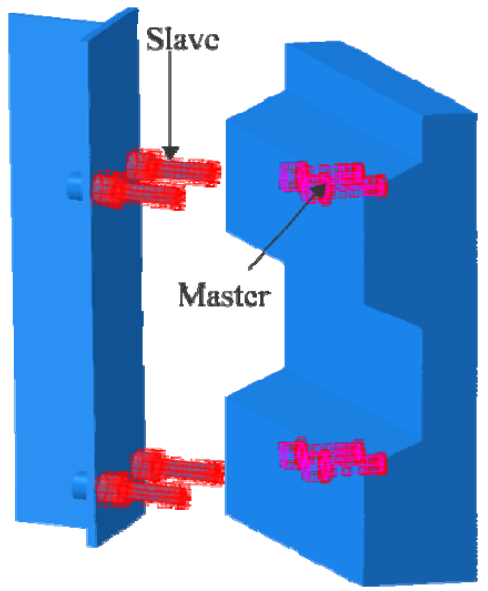

(c) Surfaces in contact interaction between concrete and bolt

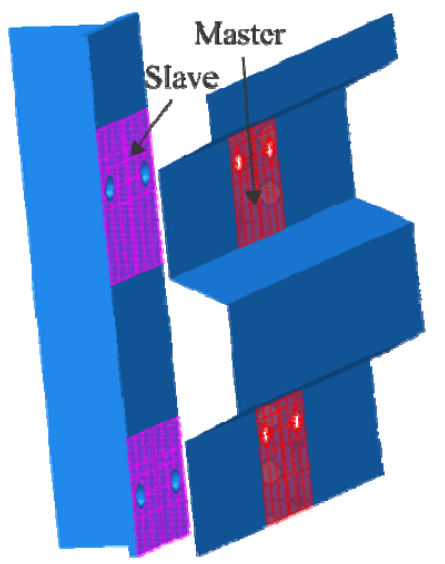

(e) Surfaces in contact interaction between decking and beam

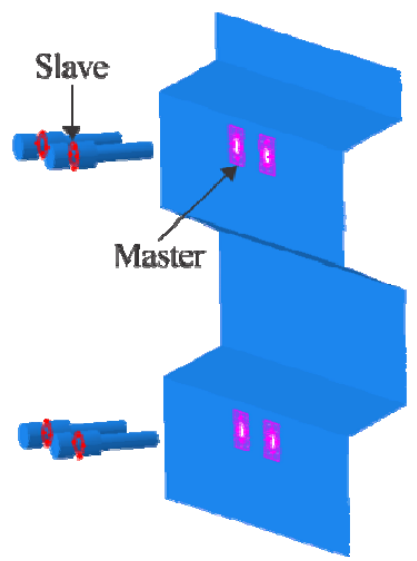

(b) Surfaces in contact interaction between decking and bolt

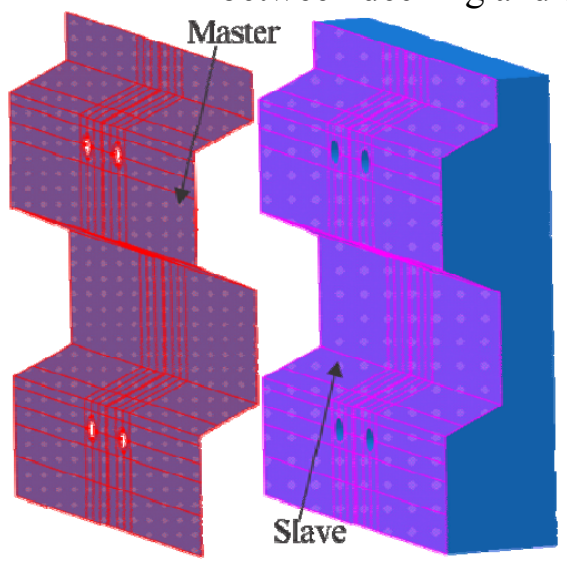

(d) Surfaces in contact interaction between decking and concrete
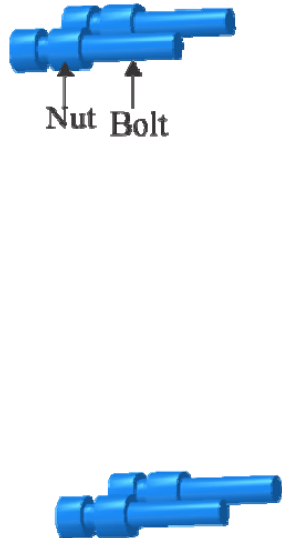

(f) Bolt and nut as a single part

Figure 5. Interaction and Constrain Surfaces 


\subsection{Material Constitutive Models}

\subsubsection{Material characteristics of structural steels}

The structural steel has the same material characteristics in compression and tension. The steel has the elastic linear relationship up to the yield stress which is followed by strain hardening before failure. Figure 6(a) depicts the two-stage linear material characteristics of steel subjected to compression, in which $\varepsilon_{s y}$ denotes for steel yield strain, $\varepsilon_{s u}$ is steel ultimate strain, $f_{s y}$ is the yield strength and $f_{s u}$ represents the steel ultimate strength. The stress-strain curves shown in Figure 6(a) are employed in the computational simulation for simulating the material behaviour of the steel beam, reinforcing bar, headed connectors and bolts.

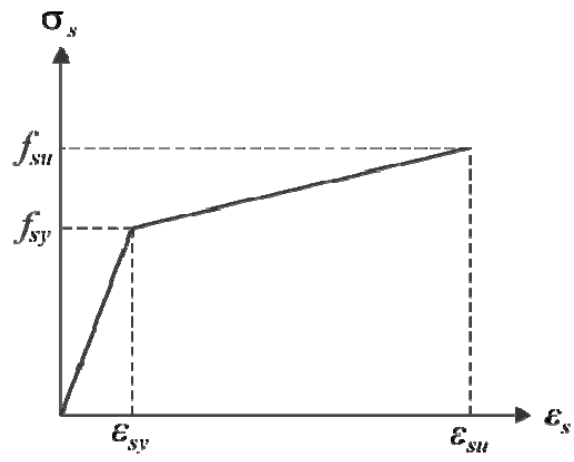

(a)

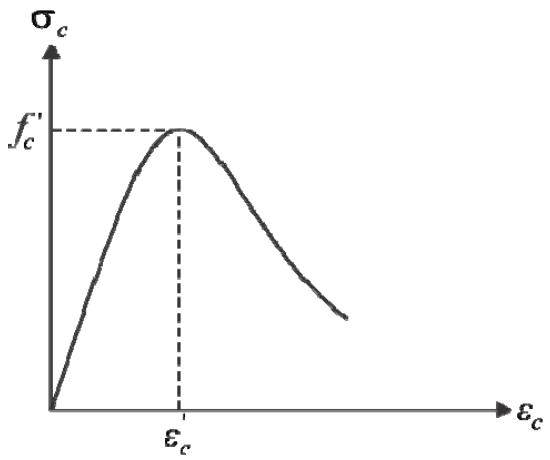

(b)

Figure 6. Material Constitutive Models:

(a) Strucutral Steel for Profiled Deck, Bolts, Steel Beam and Studs and (b) Concrete

\subsubsection{Stress-strain characteristic for concrete}

A compressive and tesnile plasticity damage model was utilised to analyse the constitutive performance of concrete. This damage is defined with the concrete compression hardening and concete tension stiffening options in Abaqus. The plasticity parameters suggested by Pathirana [10] are employed in the computational simulation for defining the plasticity parameters. The behaviour of concrete was simulated with the elastic-plastic approach with strain softerning. The stress-strain response for concrete is depcited in Figure 6(b). The concrete stress is calcuated based on the equations given by Carreira and Chu [30] as

$\sigma_{c}=\frac{\left(\frac{\varepsilon_{c}}{\varepsilon_{c}^{\prime}}\right) \lambda f_{c}^{\prime}}{\left(\frac{\varepsilon_{c}}{\varepsilon_{c}^{\prime}}\right)^{\gamma}-1+\lambda}$

in which $\varepsilon_{c}$ denotes the compressive concrete strain, $\sigma_{c}$ represents the concrete stress in compression, $f_{c}^{\prime}$ is cylinder cncrete compressive strength, $\varepsilon_{c}^{\prime}$ denotes the strain corresponding to $f_{c}^{\prime}$ and $\gamma$ is expressed by

$\gamma=1.55+\left|\frac{f_{c}^{\prime}}{32.4}\right|^{3}$

in which $f_{c}^{\prime}$ is in $\mathrm{MPa}$ and the strain $\varepsilon_{c}^{\prime}$ is taken as 0.002 . 
For concrete under tension, the stress of concrete is direct proportion to the concrete strain before concrete cracking which is taken as $0.1 f_{c}^{\prime}$. After attaining concrete cracking, the concrete stress is defined by fracture energy $\left(\mathrm{G}_{\mathrm{F}}\right)$ which is given by Bažant and Becq-Giraudon [31]

$G_{F}=\left(0.0469 d_{\max }^{2}-0.5 d_{\max }+26\right)\left(\frac{f_{c}^{\prime}}{10}\right)$

where $d_{\max }$ stands for the maximum coarse aggregate size in $\mathrm{mm}$ and it is taken as $20 \mathrm{~mm}$.

\subsubsection{Failure criteria}

The failure of the composite beams in the finite element analysis was identified by using the specific failure criteria corresponding to the ultimate strength of the various section components. The failure of the composite beam in the analysis was identified by concrete crushing, shear connection failure and buckling of steel beams. The concrete crushing was defined when the principal compressive strain at a point reached the crushing strain, equal to 0.004 . Shear connection failure was defined when the recorded slip at a shear connector reached a value of $6 \mathrm{~mm}$. Buckling of steel beams and decking can explicitly captured in Abaqus so it was identified from the deformed shape of the model [19].

\section{VERIFICATION}

The evaluation of the developed finite element models are examined by the verifications between the computational and corresponding test results. The shear connector capacities and load-slip curves of the composite metal decking beams are included in the evaluation of the finite element model. The shear connector capacities for composite metal decking beams obtained from the simulation were compared with test data in Table 2. The shear connector capacities obtained from the computational simulation agree with tested specimens. The mean shear connector capacity determined using the finite element simulation is 1.07 times the test data. The standard deviation of $P_{F E A} / P_{\text {Test }}$ is 0.09 while its coefficient of variation is 0.08 .

Table 2. Comparison of Shear Connector Capacities for Tested Specimens

\begin{tabular}{|c|c|c|c|c|c|c|c|}
\hline Test & $P_{\text {Test }}(\mathrm{kN})$ & $P_{F E A}(\mathrm{kN})$ & $P_{E C 4}(\mathrm{kN})$ & $P_{A S 2327.1}(\mathrm{kN})$ & $P_{\text {FEA }} / P_{\text {Test }}$ & $P_{E C 4} / P_{\text {Test }}$ & $P_{A S 2327.1} / P_{\text {Test }}$ \\
\hline Profiled slab & 72 & 79.3 & 66 & 68 & 1.10 & 0.92 & 0.95 \\
\hline Solid slab & 86.3 & 98.8 & 88.8 & 88 & 1.14 & 1.03 & 1.02 \\
\hline Hollow-core & 105.8 & 103.0 & 100.5 & 103 & 0.97 & 0.95 & 0.97 \\
\hline \multicolumn{5}{|l|}{ Mean } & 1.07 & 1.03 & 0.98 \\
\hline \multicolumn{5}{|c|}{ Standard deviation (SD) } & 0.09 & 0.06 & 0.04 \\
\hline \multicolumn{5}{|c|}{ Coefficient of variation $(\mathrm{CoV})$} & 0.08 & 0.06 & 0.04 \\
\hline
\end{tabular}

The load-slip curves for composite beams predicted by the computational simulation are verified by the test data provided by Uy and Bradford [24] and Mirza et al. [25]. Figure 7(a) depicts the load-slip curves for the steel-concrete composite beams determined from the finite element simulation and obtained from the experiments performed by Uy and Bradford [24] for composite beam with hollow core concrete slab. The load-slip curves determined from the finite element simulation reasonably agree with the test data. The linear elastic stiffness of the load-slip curves determined from the finite element simulation is a little lower than that of the test data. However, 
the computational load-slip response agrees with the test data near the peak load level. The finite element simulation was employed to determine the load-slip curves of the steel-concrete composite beams investigated by Mirza et al. [25]. Figure 7(b) illustrates the evaluation of tested and numerical load-slip responses for the steel-concrete composite trapezoidal metal decking slabs. The figure demonstrates that the finite element simulations predict well the load-slip response for the experimented composite beam up to the peak load level. The computed linear elastic stiffness of the steel-concrete composite beams matches with the test data. However, the tested load-slip response differs from the simulated one after attaining the ultimate load. This is due to the fact that the mircrocracks observed in the concrete resulting in the load reduction [32], while the finite element analysis does not consider the microcracks in modelling of concrete element. To further examine the evaluation of the nonlinear analysis, the computational model developed was utilised to predict the load-slip curves for the steel-concrete composite beams with re-entrant profiled steel deck tested by Mirza et al. [25]. The computational and experimental load-slip curves for composite beam with re-entrant profiled steel deck are given in Figure 7(c). It can be observed from the figure that both tested and simulated curves closely match up to the load level about $400 \mathrm{kN}$ and after that the tested value deviates from the simulated one. This is because the mircrocracks observed in the concrete resulting does not consider in modelling of concrete element.

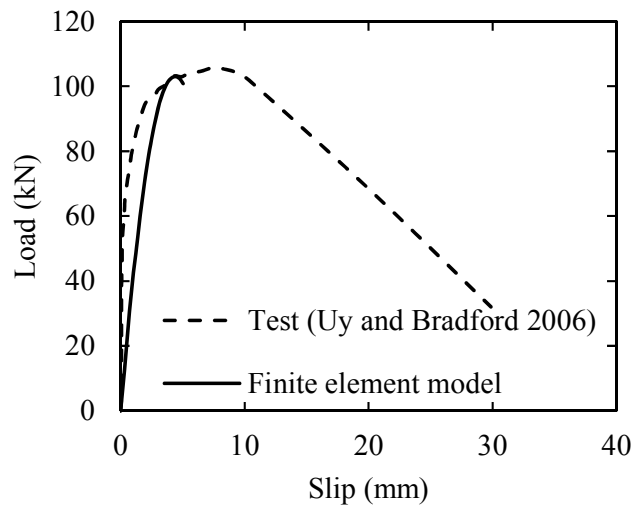

(a) Hollow core concrete slab

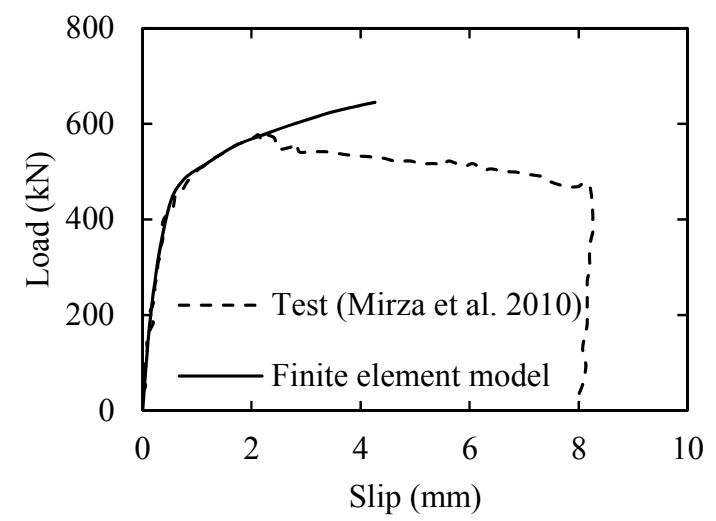

(b) Trapezoidal profiled steel deck

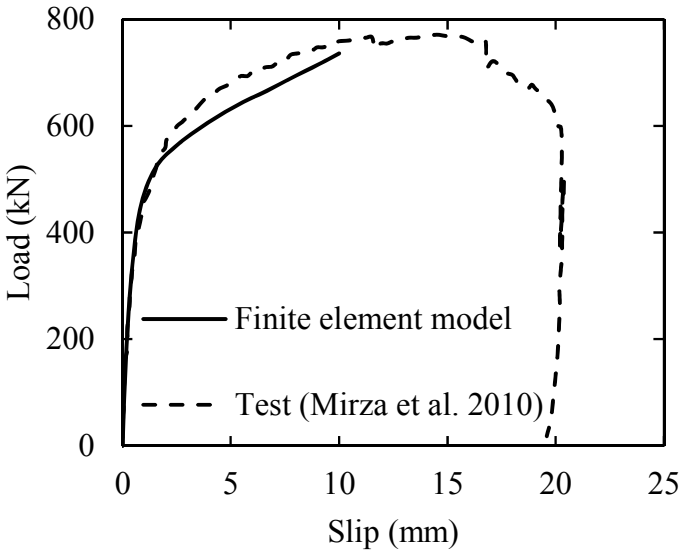

(c) Re-entrant profiled steel deck

Figure 7. Comparison of Numerical and Experimental Load-slip Curves for Composite Beams 


\section{RESULTS AND DISCUSSION}

Figure 8(a) shows a typical failure mode of concrete in composite beam. It can be seen from the figure that the bolt rotates and the inclination of the embedded nut pushes the concrete. This results in a prying out force which is responsible for concrete pull out of high strength bolt. Consequently, the failure mode is concrete failure as the removal of the bolt begins before the yielding of the shank. The excessive deflection in the concrete slab indicates the concrete slab crushing. The steel beam rupture is also observed from the excessive strain within the cross-section. It can also be seen from Figure 8(a) that the metal deck tends to separate from the concrete slab. It means that the concrete slab is delaminated from the steel deck, which results in the concrete slab tends to move up and slide over the steel deck.

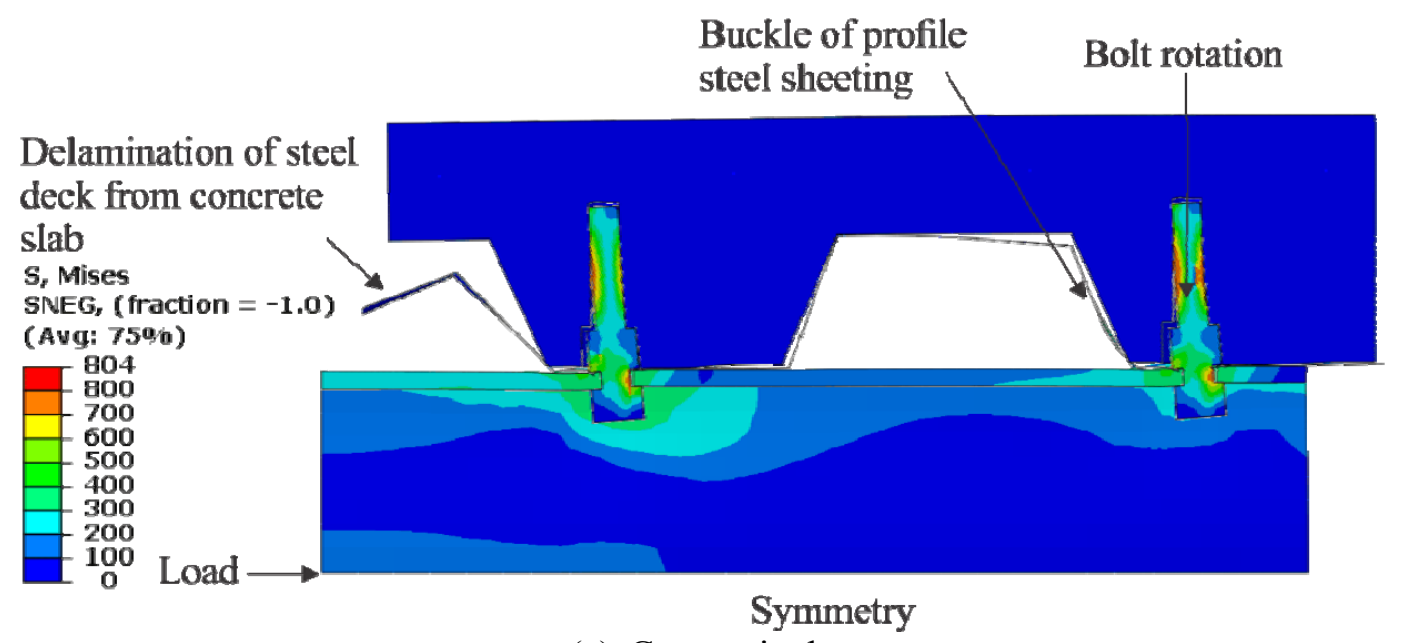

(a) Composite beam

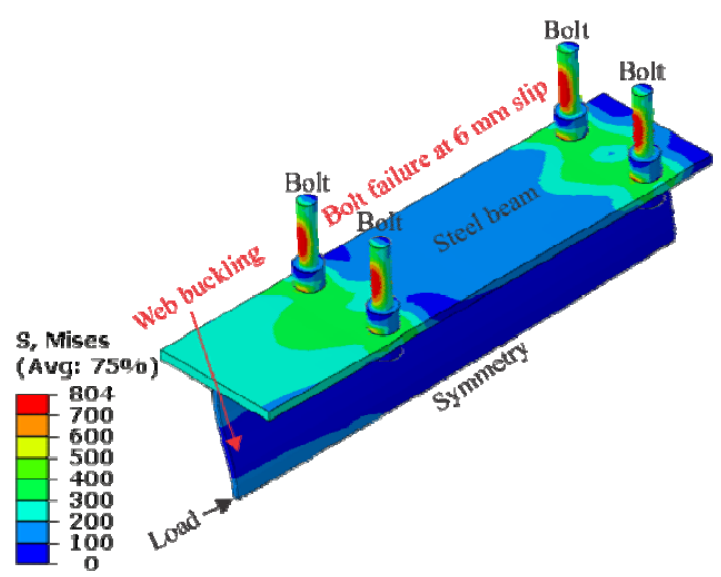

(b) Steel beam and bolts

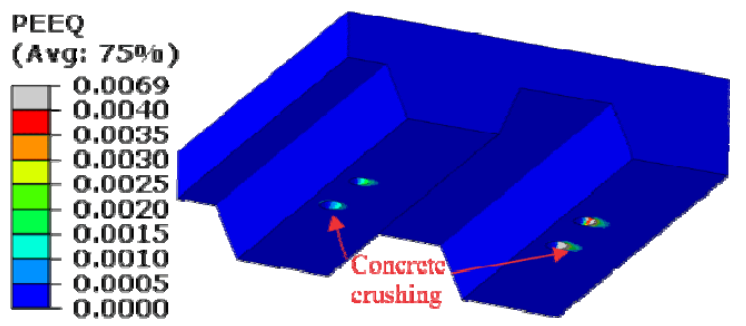

Figure 8. Failure Mode of Demountable Composite Beams with Blind Bolts

The failure mode which are observed experimentally for composite beams with bolted connectors was compared with that obtained from the finite element model. Figure 8(a) depicts the stress contour at failure of composite beams predicted from the finite element model. The failure mode of composite beam with bolted connectors was a combination of shear failure of the bolted connectors (Figure $8 \mathrm{~b}$ ) and concrete crushing failure (Figure 8c) [11]. The shear connector failure is defined at the slip of $6 \mathrm{~mm}$ as shown in Figure 8(b). The bolted connector failure results in the slab uplifting and separating from the steel beam as shown in Figure 8(a). The deformed shape of steel beam in Figure 8(b) illustrates the web buckling failure of steel beam under axial compression. It should be 
noted that the failure criteria for the concrete slab are found in the regions in front of the bolted connectors at the concrete compressive strain of 0.004 shown in Figure 8(c). The concrete crushing failure in front of bolted connectors was explained in details experimentally by Pathirana et al. [11] for the study of push-out tests with bolted connectors.

The comparison of load-deflection curves for headed stud and high strength bolts is shown in Figure 9. It can be seen from the figure that the behavior of the headed stud and bolted connectors differs substantially. The high strength bolt exhibits lower stiffness at serviceability loads compare with welded studs. Initially, the bolt experiences a slip of $1 \mathrm{~mm}$ at low loads, which is due to the clearance space surrounding the shank of the bolt. The high strength bolt was modelled to sit on the steel flange, however in practice after fastening the bolt would experience some tensile forces which would result in a higher initial stiffness until full bearing in the hole is achieved. Once closure in the bolt-to-hole clearance has been achieved the stiffness of the bolt connection increases linearly up to load level $210 \mathrm{kN}$. The bolt experiences nonlinear stiffness compared to the stud as shown in Figure 9.

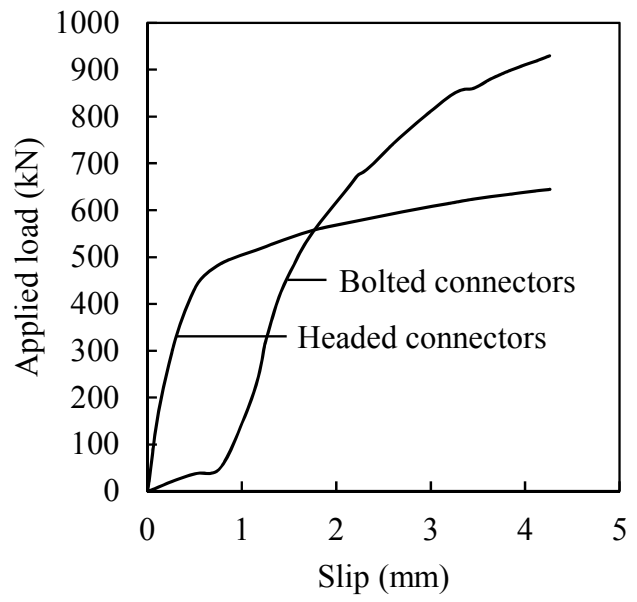

(a) Re-entrant profiled steel deck

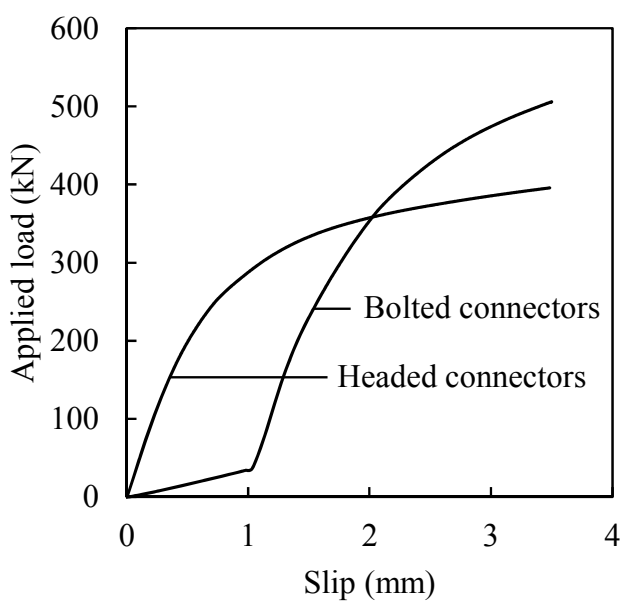

(b) Trapezodial profiled steel deck

Figrue 9. Influences of Type of Connectors on the Applied Load-slip Reponses of Demountable Composite Metal Decking Slabs

The demountability of metal decking beams is characterized by the elasticity of the bolted connectors and steel beams. This elasticity under increasing loads is maintained without undergoing the plastic deformation. The demountability of composite beams greatly depends on the elastic deformation of steel components because it cannot be achieved with large plastic deformation. The zero equivalent plastic strain (PEEQ) can be utilized to determine the plastic deformation in the composite beams. The numerical results indicate that the composite beams can be demounted for the load, where the PEEQ is observed to be zero, which is about $50 \%$ of the ultimate load and greater than typical service loads which are usually less than $40 \%$ of the ultimate load.

\section{PARAMETRIC STUDY}

The structural behaviour of demountable steel-concrete metal decking slabs is characterised by determining the slip between the composite slabs and steel beam. The slip may be described as the longitudinal displacement between the composite metal decking slabs and steel beams [33]. The behaviour of demountable composite metal decking beams depends on concrete compressive strengths, profiled steel deck thickness and shear connector positions. A small range of geometric and material parameters are covered in the experimental test program so the numerical models are 
utilised to examine the influences of the various geometric and material changes that would be reasonably be expected in Australian construction. Therefore, the geometric properties are varied consistently with the range of steel cross-section sizes which are typically available in Australia. Bolt sizes and strength are also varied with respect to those commonly available in Australian construction. Concrete and steel material properties are varied based on the current limits set in the various Australian Standards for Concrete, Steel and Composite Structures [26-29]. In this parametric study, each bolt has provided with a $1 \mathrm{~mm}$ of clearance in the oversized holes. Therefore, the initial $1 \mathrm{~mm}$ of slip occurs before the bolt contact with the side of the hole. The size of the bolted connectors, concrete slab, reinforcement and geometry of the metal decks are all kept constant in the parametric analysis.

\subsection{Influence of Concrete Slab Strength}

The elastic modulus of the concrete relies on its compressive strengths. The elastic modulus of concrete increases with an increase in the compressive strength. Therefore, elastic stiffness of the composite metal decking slabs is influenced by the concrete slab strengths. The influences of concrete slab strengths on the load-slip curves of the demountable composite metal decking slabs were studied. The normal strength concrete with compressive strengths of 27 and $32 \mathrm{MPa}$ provided in Australian Standard AS 3600-2009 (Clause 3.1) [29] was used in the computational simulations. The load-slip responses for the demountable composite metal decking slabs with different concrete slab strengths are illustrated in Figure 10. Increased concrete slab strengths tend to increase the ultimate strength of the demountable composite metal decking slabs. An increased concrete compressive strength from $25 \mathrm{MPa}$ to $32 \mathrm{MPa}$ increases the ultimate capacity by $20 \%$ for steel-concrete composite beam with trapezoidal profile steel deck while it increases the ultimate strength by $2.6 \%$ for steel-concrete composite beam with re-entrant profiled steel deck. The elastic linear stiffness of the steel-concrete composite beams with profiled steel decks increases with an increase in the concrete slab strength.

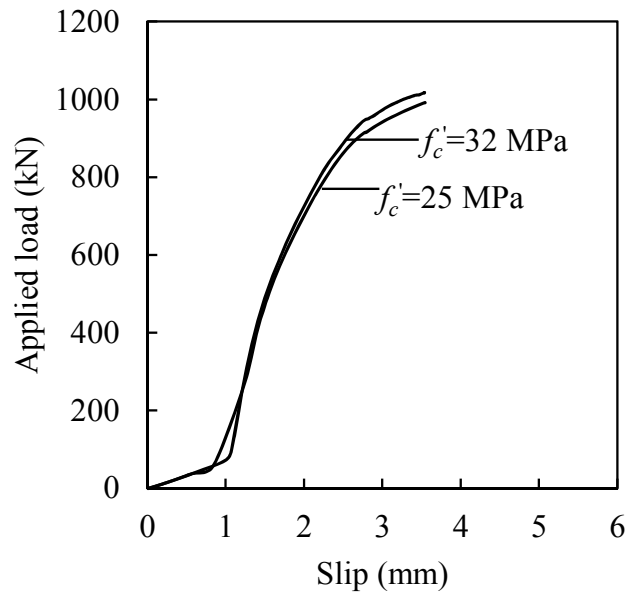

(a) Re-entrant profiled steel deck (SCB-1 and SCB-2)

Figrue 10. Influences of Concrete Slab Strengths on the Applied Load-slip Reponses of Demountable Composite Metal Decking Slabs

For re-entrant metal decking, the elastic linear stiffness of the demountable composite metal decking with concrete slab strengths of $25 \mathrm{MPa}$ and $32 \mathrm{MPa}$ is determined as $529 \mathrm{kN} / \mathrm{mm}$ and 1109 $\mathrm{kN} / \mathrm{mm}$, respectively. For trapezoidal metal decking, the initial stiffness of the demountable composite metal decking with concrete slab strengths of $25 \mathrm{MPa}$ and $32 \mathrm{MPa}$ is calculated as 439 $\mathrm{kN} / \mathrm{mm}$ and $503 \mathrm{kN} / \mathrm{mm}$, respectively. 


\subsection{Influence of Profiled Slab and Solid Slab}

The trapezoidal profiled metal decking are increasingly utilised in steel-concrete framed strucutres because they allow large spans without propping and plywood formwork. The strucutral element of the steel-concrete composite beams with trapezoidal profiled steel decking can easily be separated for subsequent reuse. This makes the composite metal decking slabs demountable at the end of its service life. The stiffness, strength and ductility of the profiled slabs and solid slabs was studied experimetally and numerically by Mirza et al. $[9,25]$. The finite element model was utilised to examine the effects of profiled slab and solid slab on the load-slip curves for composite beams. Figure 11 illustrates the effects of profiled slab and solid slab on the load-slip curves for composite beams. The figure shows that the intial stiffness for the profiled slabs and solid slabs are almost same up to the loading level of $400 \mathrm{kN}$. It can be seen from the figure that after attending the loading level of $400 \mathrm{kN}$, the profiled slab is stiffer than the solid slabs. This is due to the metal decks contribute in achieving the higher stiffnness in profile slabs when comapred with solid slabs. It should be noted that the ducitlity of the solid slabs is higher than that of the profiled slabs. This is because the solid slab failed in stud fracture while the profile slab failed by concrete crushing. Furthermore, the ultimate strength of the solid slabs is higher than that of the profiled slabs.

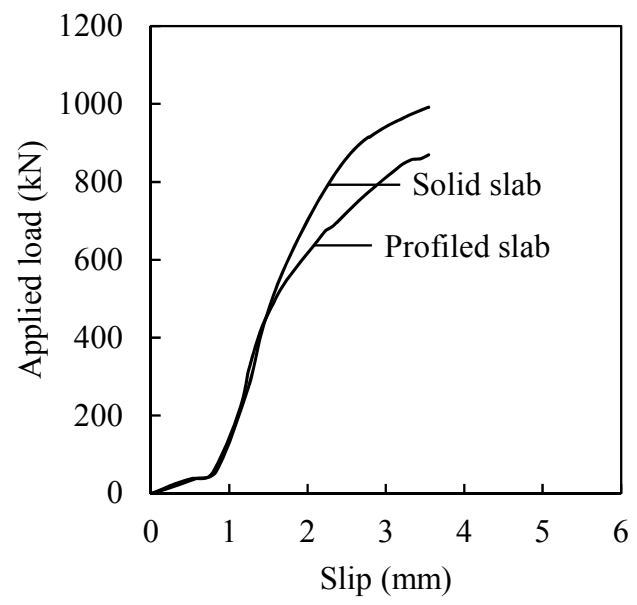

(a) Re-entrant profiled steel deck (SCB-3)

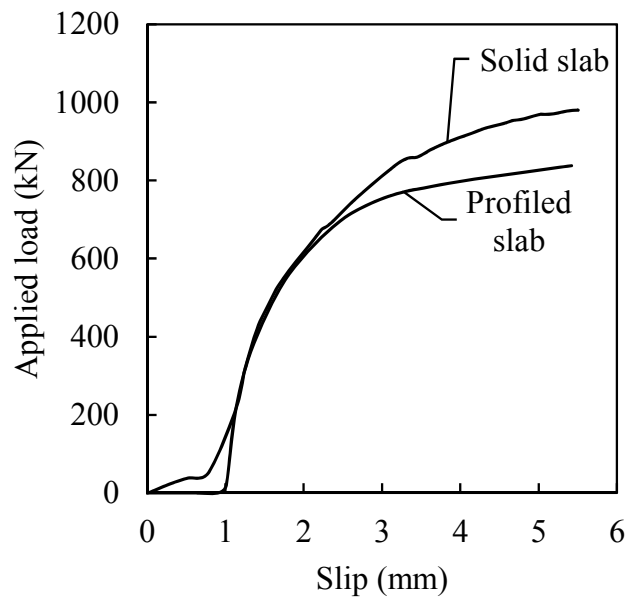

(b) Trapezodial profiled steel deck Figrue 11. Influences of Slab Types on the Applied Load-slip Reponses of Demountable Composite Metal Decking Slabs

\subsection{Effects of Shear Connector Type (Headed vs Bolted)}

Test results indicated that blind bolts can be utilised in the composite metal decking beams more efficiently than headed stud connectors [10]. Blind bolt connectors are connected through the steel beam and profiled decks into the composite slabs. These bolts can be removed as the bolt head is situatuated on the steel beam web, which allows for ease of dismantaling. The finite element model is utilised to evaluate the infleuce of using oversized holes for demountability on composite beams. Figure 9 depicts the effects of bolted shear connectors and headed studs on the load-slip curves for composite beams with steel decks. It can be observed from the figure that the use of bolted shear connectors tends to increase the ultimate strengths of composite beams. This is attributed to the fact that the yield strength of bolted shear connectors is higher than that of headed studs. It can also be seen from the figure that the initial $1 \mathrm{~mm}$ slip is noted with the use of bolted shear connectors. This is due to the oversized hole arrangements that are initially provided to achieve demountability in composite beams. The stiffness of blind bolts is much lower than that of welded shear stud connectors. 


\subsection{Effects of Profiled Metal Decking Thickness}

The finite element model was employed to study the effects of profiled steel deck thickness on the behaviour of demountable steel-concrete composite beams. The thickness of the profiled steel deck was $0.5 \mathrm{~mm}$ and $1.0 \mathrm{~mm}$. The effects of the sheeting thickness on the behaviour of centrally placed studs with the $1 \mathrm{~mm}$ rounded gap between the stud and steel beams. Figure 12 shows the load-slip curves for demountable steel-concrete composite beams with different profiled steel deck thicknesses. It can be observed that the profiled steel deck thickness does not have a significant effect on the initial stiffness of steel-concrete composite beams. An increase in the profiled steel deck thickness increases the ultimate strength of demountable composite beams. It is suggested that the behaviour of demountable structures depends on the concrete and shear connector interactions.

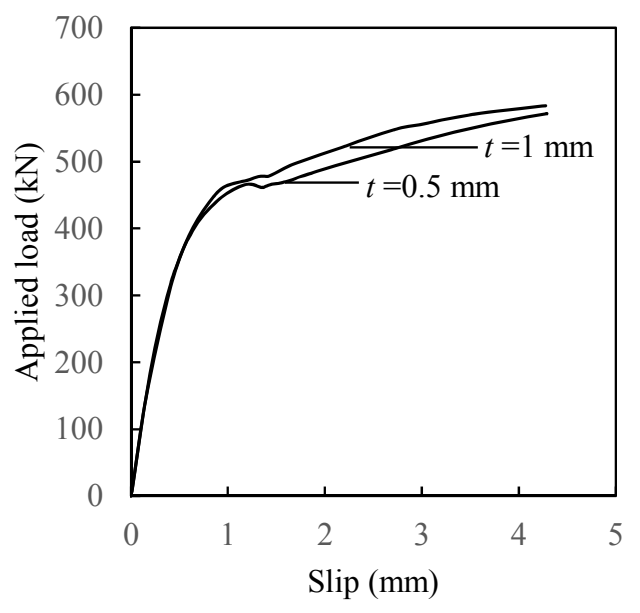

Figure 12. Influences of Profiled Thickness on the Applied Load-slip

Reponses of Demountable Composite Metal Decking Slabs

\section{DESIGN CONSIDERATIONS}

For the design of shear connectors in composite beams, the engineers are generally interested in finding the strength which each stud transfers under shear. The design equations for the shear resistance of headed studs were given in various international standards [4, 28]. The Australian Standard, AS2327.1-2003 (Clause 8.3.2.1) [28], provides the design rules for the shear connectors, which are expresses by

$f_{v s}= \begin{cases}0.63 d_{b s}^{2} f_{u c} & \text { Shear stud fails by fracture of the weld collar } \\ 0.31 d_{b s}^{2} \sqrt{f_{c j}^{\prime} E_{c}} & \text { Concrete cone failure surrounding the stud }\end{cases}$

in which $d_{b s}$ represents the shank diameter of stud, $f_{u c}$ denotes the ultimate strength of the stud material, $f_{c j}^{\prime}$ is the concrete characteristic cylinder strength, $E_{c}$ is the elastic modulus of concrete which is expressed as:

$E_{c}=\rho_{c}^{1.5} 0.043 \sqrt{f_{c j}^{\prime}}$ 
in which $\rho_{c}$ is taken as $2100 \mathrm{~kg} / \mathrm{m}^{3}$ based on the design guideline given in Australian Standard AS3600-2009 [29].

The Eurocode 4-Clause 6.6.3.1 [4] equation for the same failure modes is given by

$P_{R d}= \begin{cases}0.8 f_{u}\left(\pi d^{2} / 4\right) / \gamma_{v} & \text { Shear stud fails by fracture of the weld collar } \\ 0.29 \alpha d^{2} \sqrt{f_{c k} E_{c m}} / \gamma_{v} & \text { Concrete cone failure surrounding the stud }\end{cases}$

in which $d$ is the shank diameter which is varied between $16 \mathrm{~mm}$ and $25 \mathrm{~mm}, f_{u}$ is the ultimate strength of the study material which is not greater than $500 \mathrm{MPa}, f_{c k}$ is the concrete characteristic cylinder strength, $h$ is the overall height of stud, $\gamma_{v}$ is a partial safety factor, taken as 1.25 for the ultimate limit state and $\alpha$ is expressed by

$\alpha= \begin{cases}0.2 h / d+0.2 & \text { for } 3 \leq h / d \leq 4 \\ 1 & \text { for } h / d>4\end{cases}$

In Eq. $6, E_{c m}$ is the average concrete elastic modulus which is determined as

$E_{c m}=22000\left(\frac{f_{c k}+8}{10}\right)^{1 / 3}$

Lam et al. [1] and Lam and Uy [34] reported that the shear strength of an automatically welded stud with a normal weld collar in a hollow-core slab is determined by

$P_{R D}=0.8 f_{u}\left(\pi d^{2} / 4\right) / \gamma_{v}$

or

$P_{R D}=0.29 \alpha \beta \varepsilon d^{2} \sqrt{\omega f_{c p} E_{c p} / \gamma_{v}}$

It is should be noted that $P_{R D}$ is taken as the smaller of Eq. 7 and 8, in which $d$ is the shank diameter, $f_{u}$ is the ultimate tensile strength of stud material, $\beta$ is the reduction factor which considers the gap width $g(\mathrm{~mm})$ and it is given by $0.5(\mathrm{~g} / 70+1) \leq 1.0$, and $g \geq 30 \mathrm{~mm}, \varepsilon$ is the reduction factor which considers the diameter $\phi$ of transverse high tensile tie steel (grade 460) and is determined by $0.5(\phi / 20+1) \leq 1.0$, and $\phi \geq 8 \mathrm{~mm}, \omega$ denotes a transverse joint factor which is given by $0.5(w / 600+1), f_{c p}$ represents the average concrete cylinder strength of the insitu and precast concrete and $E_{c p}$ illustrates the average elastic modulus of the insitu and precast concrete.

The partial safety factor $\left(\gamma_{v}\right)$ is considered as 1.25 for the ultimate limit state. The existing Australian Standard, AS2327.1-2003 [28], formula given in Eq. 4 can be modified by considering the safety factor which account in Eqs. 7 and 8. Therefore, the equations for the shear strength used in Australian construction to account for the strength reductions in hollow core slab is given as 
$f_{v s}= \begin{cases}0.63 d_{b s}^{2} f_{u c} & \text { Shear stud fails by fracture of the weld collar } \\ 0.31 d_{b s}^{2} \beta \varepsilon \sqrt{\omega f_{c j}^{\prime} E_{c}} & \text { Concrete cone failure surrounding the stud }\end{cases}$

The shear strengths of connectors obtained from the experiments reported by Uy and Bradford [24] and Mirza et al. [25] are compared with the current design rule given in the AS 2327.1-2003 [28] for solid and composite slabs. The AS2327.1-2003 [28] equation for shear strengths of connectors is given as

$f_{v s}=0.63 d_{b s}^{2} f_{u c}$

in which $d_{b s}$ represents the shank diameter of headed studs.

The shear strength of bolted connectors for composite beams predicted by the finite element models and design codes are compared in Table 3. Eurocode 4 [4] and AS2327.1-2003 [28] reasonably predicts the shear strength of bolted connectors. The mean ratio of shear connector strength determined utilising the finite element model and Eurocode 4 [28] and is 1.05 with a standard deviation of 0.05 and a coefficient of variation of 0.04 . The mean ratio of shear connector capacities predicted using the finite element model and AS2327.1-2003 [28] is 1.07. The standard deviation of $P_{A S 2327.1 /} / P_{\text {Test }}$ is 0.05 and its coefficient of variation is 0.05 .

Table 3. Comparison of Shear Strengths obtained from FE Model and Design Standards for Re-entrant Profiled Steel Deck

\begin{tabular}{|c|c|c|c|c|c|c|c|}
\hline Specimens & $d_{b s}(\mathrm{~mm})$ & $f_{c}^{\prime}(\mathrm{MPa})$ & $P_{F E A}(\mathrm{kN})$ & $P_{E C 4}(\mathrm{kN})$ & $P_{A S 2327.1}(\mathrm{kN})$ & $P_{E C 4} / P_{\text {FEA }}$ & $P_{A S 2327.1} / P_{F E A}$ \\
\hline SCB-1 & 19 & 20 & 69 & 66 & 67 & 0.95 & 0.97 \\
\hline SCB-2 & 19 & 25 & 78 & 82 & 83 & 1.05 & 1.07 \\
\hline SCB-3 & 19 & 32 & 101 & 99 & 100 & 0.98 & 0.99 \\
\hline Mean & \multicolumn{7}{|l}{} \\
\hline \multicolumn{7}{|l|}{ Standard deviation (SD) } \\
\hline
\end{tabular}

\section{CONCLUSIONS}

The reuse of structural steels by using the beam-slab connectors which allow demountability has been promoted in this paper. A finite element model for simulating the behaviour of bolted shear connectors in a demountable composite beam with hollow core concrete slabs, profiled steel decks and bolted shear connectors has been developed. The bolted connectors between the steel beams and metal decking slabs allow the composite beams to be made demountable. The finite element model takes into account for the effects of nonlinear geometric and material characteristics. The finite element model can accurately predict the load-slip responses of composite beams with profiled steel deck. This paper has provided numerical results on the behaviour of demountable composite beams with various parameters including the effects of concrete compressive strengths, bolted shear connectors, welded studs, solid slabs and composite slabs. The plastic deformation in the steel-concrete composite beams was characterized using the equivalent plastic strain (PEEQ). It was found that the composite beams can be dismantled until the steel beam and bolted connectors maintain its elastic deformation without any plastic damage. The composite beams can be demounted up to about $50 \%$ of the ultimate load and this is greater than typical service loads which are usually less than $40 \%$ of the ultimate load. Eurocode 4 [4] and AS2327.1-2003 [28] give the 
reasonable prediction for the shear capacity of composite beams. The concept of reusing structural steels presented in this paper has the potential to provide significant savings and environmental benefits for construction.

\section{ACKNOWLEDGMENTS}

The research presented in this study is funded by the Australian Research Council (ARC) under its Discovery Scheme (Project No: DP140102134). The research funding is gratefully acknowledged.

\section{REFERENCES}

[1] Lam, D., Elliott, K.S. and Nethercot, D.A., "Push-off Tests on Shear Studs with Hollow-cored Floor Slabs", The Structural Engineer, 1998, Vol. 76, No. 9, pp.167-174.

[2] Lam, D., Elliott, K.S. and Nethercot, D.A., "Parametric Study on Composite Steel Beams with Precast Concrete Hollow Core Floor Slabs", Journal of Constructional Steel Research, 2000, Vol. 54, No. 2, pp. 283-304.

[3] Ellobody, E. and Young, B., "Performance of Shear Connection in Composite Beams with Profiled Steel Sheeting”, Journal of Constructional Steel Research, 2006, Vol. 62, No. 7, pp. 682-694.

[4] Eurocode 4. Design of Composite Steel and Concrete Structures-Part 1.1, General Rules and Rules for Buildings, London, UK: British Standards Institution; 2004. BS EN 1994-1-1.

[5] Pavlović, M., Marković, Z., Veljković, M. and Buđevac, D., "Bolted Shear Connectors vs. Headed Studs Behaviour in Push-out Tests", Journal of Constructional Steel Research, 2013, Vol. 88, pp. 134-149.

[6] Dai, X.H., Lam, D. and Saveri, E., "Effect of Concrete Strength and Stud Collar Size to Shear Capacity of Demountable Shear Connectors", Journal of Structural Engineering, ASCE, 2015, Vol. 141, No. 11, 04015025.

[7] Rahman, N., Lam, D., Dai, X. and Ashour, A.F., "Experimental Study on Demountable Shear Connectors in Composite Slabs with Profile Decking", Journal of Constructional Steel Research, 2016, Vol. 122, pp. 178-189.

[8] Moynihan, M.C. and Allwood, J.M., "Viability and Performance of Demountable Composite Connectors", Journal of Constructional Steel Research, 2014, Vol. 99, pp. 47-56.

[9] Mirza, O. and Uy, B., "Effects of Strain Regimes on the Behaviour of Headed Stud Shear Connectors for Composite Steel-concrete Beams", Advanced Steel Construction, 2010, Vol. 6, No. 1, pp. 635-661.

[10] Pathirana, S.W., Uy, B., Mirza, O. and Zhu, X., "Flexural Behaviour of Composite Steel-concrete Beams Utilising Blind Bolt Shear Connectors", Engineering Structures, 2016, Vol. 114, pp. 181-194.

[11] Pathirana, S.W., Uy, B., Mirza, O. and Zhu, X., "Bolted and Welded Connectors for the Rehabilitation of Composite Beams", Journal of Constructional Steel Research, 2016, Vol. 125, pp. 61-73.

[12] Loh, H.Y., Uy, B. and Bradford, M.A., "The Effects of Partial Shear Connection in Composite Flush End Plate Joints Part I - Experimental Study", Journal of Constructional Steel Research, 2006, Vol. 62, No. 4, pp. 378-390.

[13] Wang, J.F., Han, L.H. and Uy, B., "Behaviour of Flush End Plate Joints to Concrete-filled Steel Tubular Columns”, Journal of Constructional Steel Research, 2009, Vol. 65, No, 4, pp. 925-939. 
[14] Mirza, O. and Uy, B., "Behaviour of Composite Beam-column Flush End-plate Connections subjected to Low-probability, High-consequence Loading", Engineering Structures, 2011, Vol. 33, No. 2, pp. 647-662.

[15] Liu, X., Bradford, M.A. and Lee, M.S.S., "Behavior of High-strength Friction-grip Bolted Shear Connectors in Sustainable Composite Beams", Journal of Structural Engineering, 2015, Vol. 114, No. 6, 04014149.

[16] Ataei, A., Bradford, M.A., Liu, X., "Experimental Study of Flush End Plate Beam-to-column Composite Joints with Precast Slabs and Deconstructable Bolted Shear Connectors", Structures, 2016, Vol. 7, pp. 43-58.

[17] Ban, H., Uy, B., Pathirana, S. W., Henderson, I., Mirza, O. and Zhu, X., "Time-dependent Behaviour of Composite Beams with Blind Bolts under Sustained Loads", Journal of Constructional Steel Research, 2015, Vol. 112, pp. 196-207.

[18] Uy, B., Patel, V., Li, D. and Aslani, F., "Behaviour and Design of Connections for Demountable Steel and Composite Structures", Structures, 2017, Vol. 9, pp. 1-12.

[19] Vasdravellis, G., Uy, B., Tan, E.L., Kirkland, B., "The Effects of Axial Tension on the Hogging-moment Regions of Composite Beams", Journal of Constructional Steel Research, 2012, Vol. 68, pp. 20-33.

[20] Vasdravellis, G., Uy, B., Tan, E.L., Kirkland, B., "The Effects of Axial Tension on the Sagging-moment Regions of Composite Beams", Journal of Constructional Steel Research, 2012, Vol. 72, pp. 240-253.

[21] Vasdravellis, G., Uy, B., Tan, E.L., Kirkland, B., "Behaviour and Design of Composite Beams Subjected to Negative Bending and Compression", Journal of Constructional Steel Research, 2012, Vol. 79, pp. 34-47.

[22] Vasdravellis, G., Uy, B., Tan, E.L., Kirkland, B., "Behaviour and Design of Composite Beams subjected to Sagging Bending and Axial Compression", Journal of Constructional Steel Research, 2015, Vol. 110, pp. 29-39.

[23] ABAQUS User's Manual, Version 6.12-1, Hibbit, Karlsson and Sorensen, Inc., Pawtucket, R.I., 2012.

[24] Uy, B. and Bradford, M., "Composite action of Structural Steel Beams and Precast Concrete Slabs for the Flexural Strength Limit State", Australian Journal of Structural Engineering, 2006, Vol. 7, No. 2, pp. 1-10.

[25] Mirza, O., Uy, B. and Ha, L., "Time-dependent Analysis of Composite Steel-concrete Beams with Innovative Deep Trapezoidal Decks", Steel and Composite Structures-Proceedings of the $4^{\text {th }}$ International Conference, 2010.

[26] Standard Australia, Australian Standard AS 3600-2009 Concrete Structures, 2009, Australia

[27] Standard Australia, Australian Standard, Steel Structures, AS4100-1998 (incorporating Amendment 1-2012), 1998, Australia.

[28] Standard Australia, AS/NZS 2327 Composite Structures Part 1: Simply supported Beams, Sydney, 2003.

[29] AS 3600-2009. Concrete Structures, Sydney, New South Wales, Australia: Standard Australia; 2009.

[30] Carreira, D. J. and Chu, K. H., "Stress-strain Relationship for Plain Concrete in Compression", ACI Journal, 1985, Vol. 82, No. 6, pp. 797-804.

[31] Bažant, Z. P. and Becq-Giraudon, E., "Statistical Prediction of Fracture Parameters of Concrete and Implications for Choice of Testing Standard", Cement and Concrete Research, 2002, Vol. 32, No. 4, pp. 529-556.

[32] Mirza, O. and Uy, B., "Numerical Modelling of Short and Long Term Behaviour of Headed Stud Shear Connector in Composite Steel-concrete Beams", Incorporating Sustainable Practice in Mechanics of Structures and Materials, CRC press, 2010, pp. 91-96. 
[33] Kwon, G., Engelhardt, M.D. and Klingner, R.E., "Behavior of Post-installed Shear Connectors under Static and Fatigue Loading", Journal of Constructional Steel Research, 2010, Vol. 66, No. 4, pp. 532-541.

[34] Lam, D. and Uy, B., "Recent Research and Development in Composite Steel Beams with Precast Hollow Core Slabs", Steel Construction-Journal of the Australian Institute of Steel Construction, 2003, Vol. 37, No. 2, pp. 1-13. 